\title{
GROWTH AND CHARACTERIZATION OF CdS DOPED KDP SINGLE CRYSTALS
}

\author{
O V Mary Sheeja ${ }^{1}$, C K Mahadevan ${ }^{2}$ \\ ${ }^{1,2}$ Physics Research Centre, S.T.Hindu College, Nagercoil-629002, Tamilnadu, India. \\ ovsheeja@yahoo.in,mahadevan58@yahoo.co.in
}

\begin{abstract}
Pure and $C d S$ added potassium dihydrogen phosphate (KDP) single crystals (a total of six) have been grown by the slow evaporation method at room temperature. Powder X-ray diffraction, atomic absorption spectroscopic and Fourier transform infrared spectral measurements were done to characterize the grown crystals structurally and chemically. Thermal and mechanical stabilities were understood by making respectively the thermogravimetric and microhardness measurements. The optical transmittance and second harmonic generation efficiency were understood by making respectively the UV-Vis-NIR spectral and nonlinear optical measurements. The AC and DC electrical measurements made on all the six grown single crystals indicate a normal dielectric behaviour. The electrical parameters, viz. dielectric constant, dielectric loss factor and AC and DC electrical conductivities are found to increase with the increase in temperature in the range $\left(40-150^{\circ} \mathrm{C}\right)$ considered in the present study. The estimated $A C$ and DC activation energies are found to vary nonlinearly with the impurity concentration.
\end{abstract}

Keywords: Crystal growth, Doped crystals, KDP crystals, Physical properties, X-ray diffraction.

\section{INTRODUCTION}

Potassium dihydrogen phosphate $\left(\mathrm{KH}_{2} \mathrm{PO}_{4}, \mathrm{KDP}\right)$ crystal is widely used and well studied nonlinear optical (NLO) material. The unique combination of properties like wide range of transparency, relatively high magnitude of the quadratic nonlinear susceptibility, electrooptical and piezooptical effect, as well as the possibility of growing wide aperture crystals make KDP single crystals to have a special attention of the researchers. Currently, KDP single crystals are used in industrial laser facilities as a frequency multiplier, parametric amplifier and electrooptical shutters. Many attempts have been made to modify its properties either by changing the growth condition or by adding different impurities [1-7].

The structure of KDP type ferroelectrics is defined by their hydrogen bonds and, consequently, such matrixes readily accept both organic and inorganic impurities, e.g. $\mathrm{KCl}$, oxalic acid, $\mathrm{Al}_{2} \mathrm{O}_{3}$, amaranth, rhodamine $\mathrm{B}$, methyl orange, Lglutamic acid, L-histidine, L-valine [8-11]. Recently, the effect of $\mathrm{TiO}_{2}$ (prepared as nanoparticles) on the functional properties of KDP single crystals have been studied [12-16]. It has been reported that the composite system $\mathrm{KDP}: \mathrm{TiO}_{2}$ has giant nonlinear optical response. The influence of incorporated $\mathrm{Al}_{2} \mathrm{O}_{3} \cdot \mathrm{nH}_{2} \mathrm{O}$ nanoparticles on the growth kinetics of KDP crystal faces and crystal perfection were investigated [17].

The synthesis and properties of highly luminescent II-VI compound semiconductor nanoparticles have been extensively investigated from the basic research point of view to the application field. With the miniaturization of the particles the band gap expands and the energy level of the core band shift towards higher binding energy and, subsequently, some physical properties change. Electron and phonon confinement is possible in II-VI compound semiconductors when size of particles becomes less than the Bohr radius of the bulk crystal exciton. This leads to new physical properties and, consequently, new applications arise in telecommunications and transmission [18].

A strong interest has been devoted to nanocrystals (NCs) of semiconductors embedded in wide gap matrix, such as glass [19-21]. ZnO nanocrystals have been successfully embedded in melt-grown $\mathrm{KBr}$ crystals [22]. Boudine etal. [23-25] have analysed alkali halide crystals, viz. $\mathrm{NaCl}, \mathrm{KCl}, \mathrm{KBr}$ doped with II-VI compound semiconductors, viz. CdTe and CdS. Recently, a study [26] has been performed to prove the possibility of embedding $\mathrm{CdTe}$ nanoparticle in KDP crystalline matrix. Such crystals were able to capture $2 \mathrm{~nm}$ $250 \mu \mathrm{m}$ particles. Balasubramanian et al [27] have reported that the density and mechanical properties of triglycine sulphate (TGS) crystals were improved by doping with watersoluble $\mathrm{CdS}$ nanoparticle dispersed in water.

The cadmium sulphide $(\mathrm{CdS})$ is one of the interesting materials used in optoelectronics, electroluminescence and in laser devices [28-30]. The band gap energy $\left(\mathrm{E}_{\mathrm{g}}\right)$ of $\mathrm{CdS}$ at room temperature is about $2.5 \mathrm{ev}$ [31] and the exciton Bohr radius is $3 \mathrm{~nm}$ [32]. It is expected to be worth and interesting to dope KDP crystal with CdS. KDP single crystals are grown 
normally by using the solution methods at near ambient temperatures. Generally II-VI compounds including $\mathrm{CdS}$ do not dissolve in water. Now, the question is how to dissolve $\mathrm{CdS}$ in the aqueous solution of KDP used for the growth of single crystals. So, finding a way to do the above is one of the challenges of recent research activities.

During the wet chemical synthesis of nanoparticles, organic stabilizers are usually used to prevent them from aggregating by capping their surface. Moreover, the introduction of stabilizers influences on the chemical and physical properties of II-VI compound semiconductor materials, from stability to solubility and to light emission. However, only few reports describe the preparation of water-soluble $\mathrm{CdS}$ nanoparticles with complex molecules [33-34]. Tang et al [35] found that ethylene diamine capping enhances the solubility of $\mathrm{CdS}$ nanoparticles in water.

In an attempt to introduce $\mathrm{CdS}$ as dopant into the KDP crystal matrix, in the present work, we have prepared ethylene diamine capped $\mathrm{CdS}$ nanoparticles by a simple solvothermal method using a domestic microwave oven (Mahadevan's method [36-38]). Pure and CdS doped KDP single crystals (a total of six) were grown and characterized chemically, structurally, thermally, mechanically, optically and electrically by using the available standard methods. The results obtained are reported herein and discussed.

\section{EXPERIMENTAL DETAILS}

\subsection{Preparation of CdS Nanoparticles}

Mahadevan's method [36-38] was adopted to obtain the ethylene diamine capped $\mathrm{CdS}$ nanoparticles from cadmium acetate dihydrate and thiourea (both AR grade) dissolved in double distilled water in the presence of ethylene diamine. The solubility was found to be $0.33 \mathrm{~g} / 100 \mathrm{ml}$ of $\mathrm{H} 2 \mathrm{O}$. Details on the preparation and characterization of $\mathrm{CdS}$ nanoparticles appear elsewhere.

\subsection{Growth of KDP Single Crystals}

Pure and CdS doped KDP single crystals were grown by the free (slow) evaporation method from saturated aqueous solutions of KDP. CdS nanoparticles $(0.1 \mathrm{~g})$ were dissolved in double distilled water $(100 \mathrm{ml})$ and used as the dopant. Five different dopant concentrations were considered by adding 2,3,4,5 and $6 \mathrm{ml}$ of the above solution to the KDP solution. The above doped solutions were stirred well and then allowed to equilibrate in the dust free zone at room temperature. Small crystals appeared in the beginning stage due to slow evaporation and grew larger in a considerable time. The grown crystals are represented in the same order as Pure KDP, CKDP-1, CKDP-2, CKDP-3, CKDP-4 and CKDP-5.

\subsection{Characterizations Made}

X-ray powder diffraction (PXRD) data were collected for the powdered crystal samples (all the six) using an automated Xray powder diffractometer (X-PERT PRO PANalytical) with monochromated $\mathrm{CuK}_{\alpha}$ radiation $(\lambda=1.54056 \AA)$ in the $2 \theta$ range $10-70^{\circ}$. The reflections were indexed by following the procedures of Lipson and Steeple [39]. Lattice parameters along with estimated standard deviation (e.s.d.s) were also determined from the indexed data. Fourier transform infrared (FTIR) spectra were recorded for the Pure KDP and CKDP-5 crystals by the $\mathrm{KBr}$ pellet technique using a Perkin Elmer FTIR spectrometer in the wavenumber range $400-4000 \mathrm{~cm}^{-1}$. Atomic absorption spectroscopic (AAS) measurements were carried out for the doped crystals using an AAS spectrometer (model AA-6300).

Thermogravimetric analysis (TGA) and differential thermal analysis (DTA) were carried out for the Pure KDP and CKDP5 crystals using a thermal analyser ( model SDT-Q600) in the nitrogen atmosphere in the temperature range of room temperature to $900^{\circ} \mathrm{C}$ at a heating rate of $10^{\circ} \mathrm{C} / \mathrm{min}$. UV-VisNIR transmission spectra for all the six crystals were recorded in the wavelength range 190-1100nm using a Perkin Elmer Lambda35 spectrophotometer. The second harmonic generation (SHG) property was tested for all the six grown crystals by carrying out the Kurtz and Perry [40] powder SHG test using a Q-switched Nd:YAG laser (1064nm) ( supplied by Spectra Physics, USA). Vicker's microhardness measurements were carried out on the (100) face of all the six crystals grown using a SHIMADZU HMV-2T microhardness tester with a diamond indentor.

Crystals with large surface defects-free (i.e. without any pit or crack or scratch on the surface, tested with a travelling microscope) size $(>3 \mathrm{~mm})$ were selected and used for the AC and DC electrical measurements. The extended portions of the crystals were removed completely and the opposite faces were polished and coated with good quantity graphite to obtain a good conductive surface layer. The dimension of the crystal were measured using a traveling microscope (Least count $=0.001 \mathrm{~cm})$. The DC electrical conductivity measurements were carried out to an accuracy of $\pm 2 \%$ for all the six grown crystals along both a- and c- directions at various temperatures ranging from $40-150^{\circ} \mathrm{C}$ by the conventional two-probe method using a million megohm meter in a way similar to that followed by Mahadevan and his co-workers [41-43]. The DC conductivity $\left(\sigma_{\mathrm{dc}}\right)$ of the crystal was calculated using the relation:

$$
\sigma_{\mathrm{dc}}=\mathrm{d}_{\mathrm{crys}} /\left(\mathrm{RA}_{\mathrm{crys}}\right)
$$

Where $R$ is the measured resistance, $d_{\text {crys }}$ is the thickness of the sample crystal and $\mathrm{A}_{\text {crys }}$ is the area of the face of the crystal in contact with the electrode. The capacitance $\left(\mathrm{C}_{\text {crys }}\right)$ and dielectric loss factor $(\tan \delta)$ measurements were carried 
out for all the six grown crystals to an accuracy of $\pm 2 \%$ by the parallel plate capacitor method using an LCR meter (Systronics make) with a frequency of $1 \mathrm{kHz}$ at various temperatures ranging from $40-150^{\circ} \mathrm{C}$ along both a- and cdirections in a way similar to that followed by Mahadevan and his co-workers [44-46]. In both the DC and AC electrical measurements, the observations were made while cooling the sample crystal and the temperature was controlled to an accuracy of $\pm 1 \%$. The air capacitance $\left(\mathrm{C}_{\mathrm{air}}\right)$ was also measured but only at $40^{\circ} \mathrm{C}$ since the temperature variation of $\mathrm{C}_{\mathrm{air}}$ was found to be negligible. As the crystal surface area touching the electrode was smaller than the plate (electrode) area of the cell, the dielectric constant of the crystal $\left(\varepsilon_{\mathrm{r}}\right)$ was calculated using Mahadevans's formula $[47,48]$

$$
s_{r}=\left\{\frac{C_{\text {orys }}-C_{\text {adr }}\left(1-\frac{A_{C r y s}}{A_{\text {air }}}\right)}{C_{\text {atr }}}\right\}\left(\frac{A_{\text {air }}}{A_{\text {Crys }}}\right)
$$

where $\mathrm{C}_{\text {crys }}$ is the capacitance with crystal (including air), $\mathrm{C}_{\mathrm{air}}$ is the capacitance of air and $\mathrm{A}_{\mathrm{air}}$ is the area of the electrode. The AC electrical conductivity $\left(\sigma_{\mathrm{ac}}\right)$ was calculated using the relation:

$$
\sigma_{\mathrm{ac}}=\varepsilon_{0} \varepsilon_{\mathrm{r}} \omega \tan \delta
$$

where $\varepsilon_{0}$ is the permittivity of free space and $\omega$ is the angular frequency of the applied field.

\section{RESULTS AND DISCUSSION}

\subsection{Crystals Grown}

Figure 1 shows a photograph of the sample crystals grown in the present study. All the six crystals grown are found to be stable in atmospheric air, colourless and transparent.

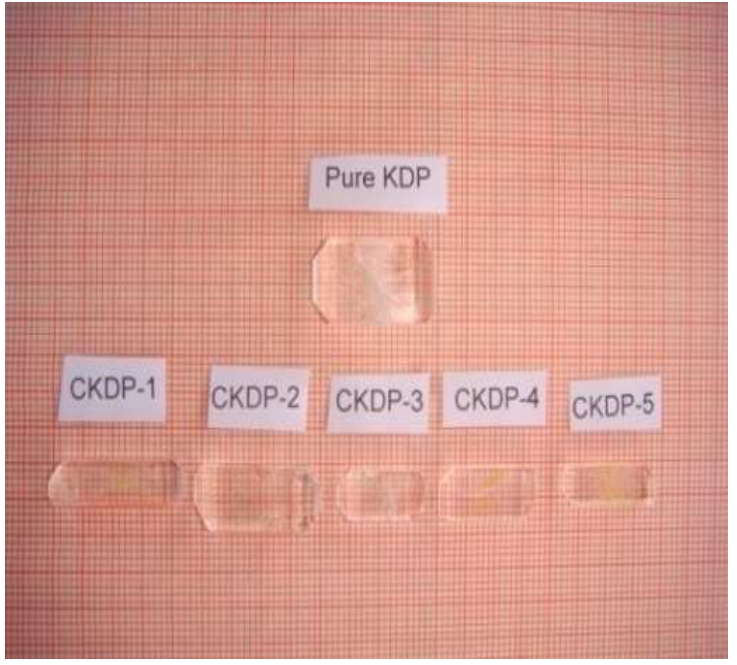

Fig-1: Photograph of the crystals grown

\subsection{Lattice Variation and Chemical Composition}

The indexed PXRD patterns observed in the present study are shown in Figure 2. Appearance of strong and sharp peaks confirms the crystalline nature of the grown crystals. The average lattice parameters obtained from PXRD data along with the $\mathrm{Cd}$ atom contents of doped crystals obtained through the AAS measurements are provided in Table 1.

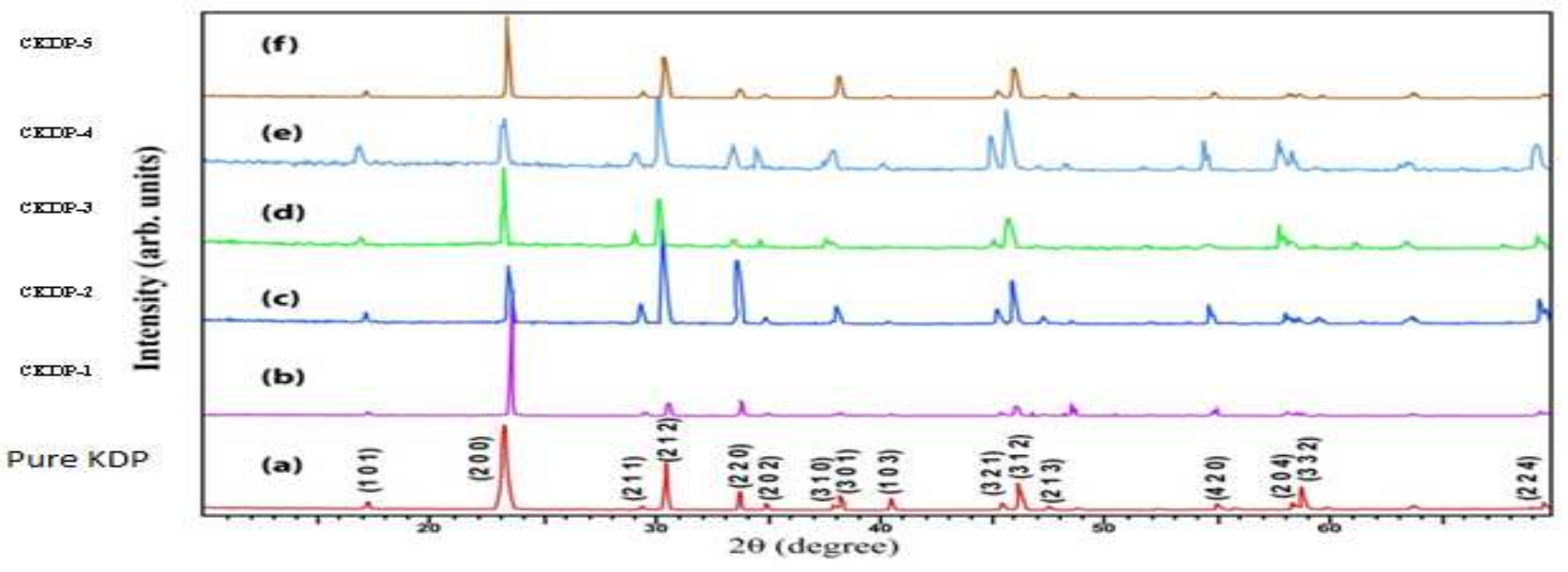

Fig-2: PXRD patterns observed for pure and CdS doped KDP crystals 
Table-1: The observed lattice average parameters and $\mathrm{Cd}$ atom contents. The e.s.d.s are in parentheses

\begin{tabular}{|c|c|c|c|c|}
\hline \multirow{2}{*}{ Crystal } & \multicolumn{3}{|c|}{ Lattice parameters } & $\begin{array}{c}\text { Cd atom } \\
\text { content } \\
\text { (ppm) }\end{array}$ \\
\cline { 2 - 5 } & $\mathrm{a}(\AA)$ & $\mathrm{c}(\AA)$ & $\begin{array}{c}\text { Volume } \\
\left(\AA^{3}\right)\end{array}$ & \\
\hline Pure KDP & $7.413(8)$ & $6.942(9)$ & 381.5 & - \\
\hline CKDP-1 & $7.441(4)$ & $6.964(4)$ & 385.6 & 4.93 \\
\hline CKDP-2 & $7.476(8)$ & $6.997(10)$ & 391.1 & 6.54 \\
\hline CKDP-3 & $7.552(9)$ & $6.884(11)$ & 392.6 & 7.45 \\
\hline CKDP-4 & $7.511(8)$ & $7.072(6)$ & 398.9 & 7.95 \\
\hline CKDP-5 & $7.544(11)$ & $7.052(8)$ & 401.3 & 8.96 \\
\hline
\end{tabular}

The average lattice parameters observed in the present study (see Table 1) for the pure KDP crystal agree well with that reported in the literature [49]: $a=7.3930 \AA$ and $c=7.0484 \AA$. This confirms the identity of the substance. The observed increase of lattice volume caused by the impurity addition indicates that the impurity molecules have entered into the KDP crystal matrix. Moreover, it can be seen that the lattice volume varies further with the increase in impurity concentration. The $\mathrm{Cd}$ atom contents observed (see Table 1) endorse this result. So, the present study indicates that it is possible that $\mathrm{CdS}$ can be doped to KDP crystal.

Figure 3 shows the FTIR spectra observed for the Pure KDP and CKDP-5. The vibrational band assignments are provided in Table 2. Significant difference could not be observed for the doped crystals as the impurity concentrations considered are small. The spectrum observed for the Pure KDP compares well with that reported in the literature which again confirms the material of the crystal. The vibrational band assignments reported for Pure KDP in the literature [50] are also given in Table 2 for comparison.

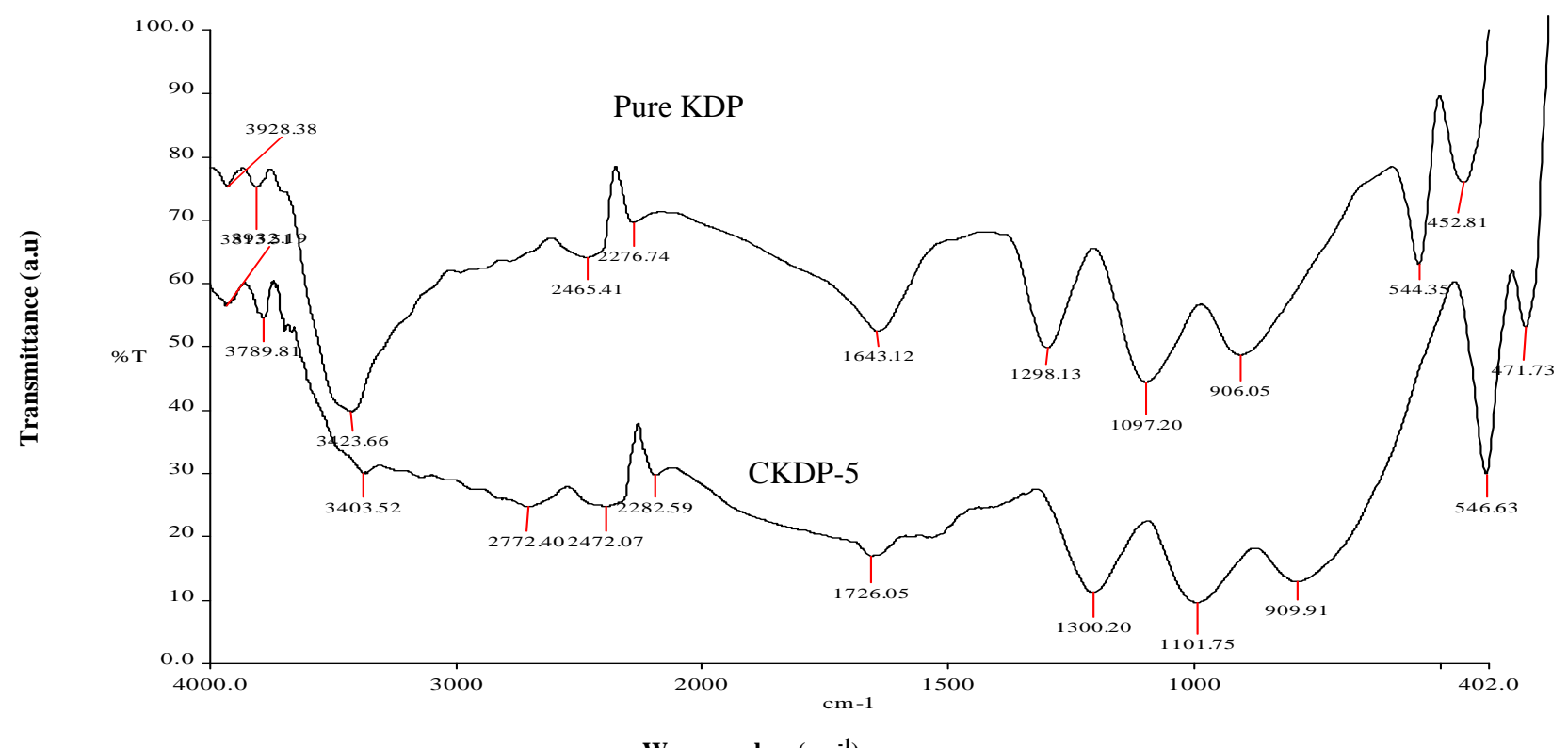

Wavenumber $\left(\mathrm{cm}^{-1}\right)$

Fig-3: FTIR spectra observed for the Pure KDP and CKDP-5 crystals 
Table-2: The vibrational band assignments

\begin{tabular}{|c|c|c|l|}
\hline \multicolumn{2}{|c|}{ Wavenumbers $\left(\mathrm{cm}^{-1}\right)$ for } & \multicolumn{1}{|}{ Assignment } \\
\cline { 1 - 2 } KDPre & CKDP-5 & $\begin{array}{c}\text { Pure KDP } \\
{[50]}\end{array}$ & \multicolumn{1}{|c|}{} \\
\hline 3928 & 3932 & 3941 & O-H stretching \\
\hline 3813 & 3789 & - & Free O-H stretching \\
\hline 3423 & 3403 & 3428 & $\begin{array}{l}\text { Hydrogen bonded O-H } \\
\text { stretching }\end{array}$ \\
\hline- & 2772 & 2782 & $\begin{array}{l}\text { P-O-H } \\
\text { stretching }\end{array}$ \\
\hline 2465 & 2472 & 2464 & $\begin{array}{l}\text { O=P-OH } \\
\text { stretching }\end{array}$ \\
\hline 2276 & 2282 & 2354 & P-O-H bending \\
\hline- & 1726 & - & O=P-O stretching \\
\hline 1643 & - & 1642 & $\begin{array}{l}\text { O=P-OH } \\
\text { stretching }\end{array}$ \\
\hline 1298 & 1300 & 1300 & P=O stretching \\
\hline 1097 & 1101 & 1095 & P=O stretching \\
\hline 906 & 909 & 904 & $\begin{array}{l}\text { P=O-H } \\
\text { stretching }\end{array}$ \\
\hline 544 & 546 & 542 & HO-P-OH bending \\
\hline 452 & 471 & 458 & PO 4 stretching \\
\hline
\end{tabular}

\subsection{Thermal Properties}

Figure 4 shows the TGA and DTA curves observed for the Pure KDP and CKDP-5 crystals. It can be understood that the Pure KDP and CdS doped KDP crystals are thermally stable up to $212^{\circ} \mathrm{C}$ and $211^{\circ} \mathrm{C}$ respectively. Beyond that, the pure or doped KDP decomposes as expected.

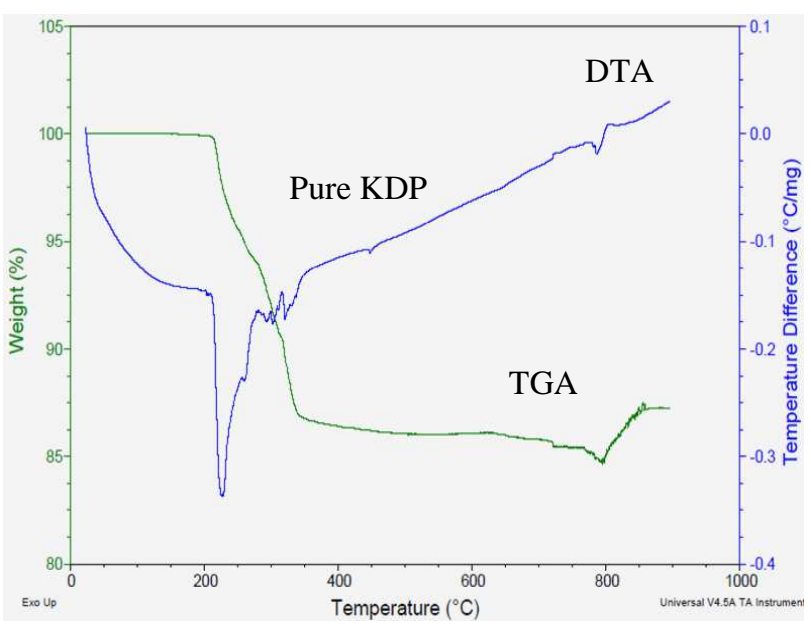

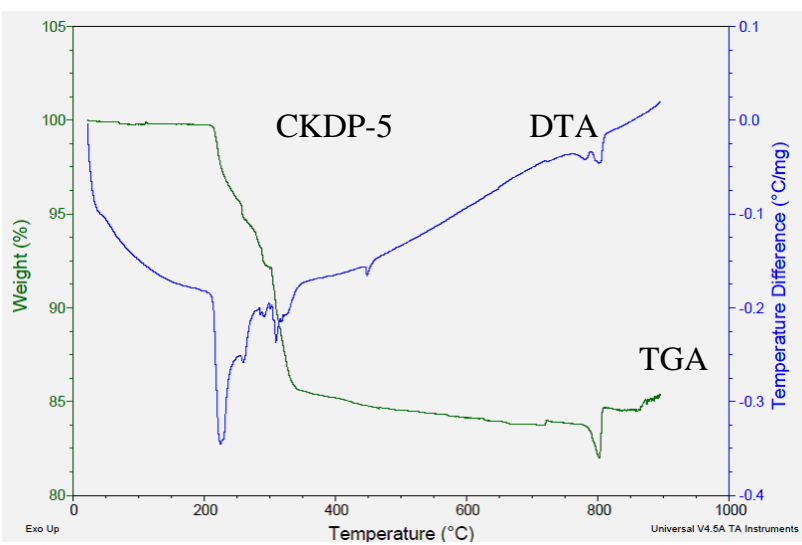

Fig-4: TGA and DTA curves observed for the Pure KDP and CKDP-5 crystals

\subsection{Optical and Mechanical Properties}

Figure 5 shows the UV-Vis-NIR transmittance spectra for all the six crystals grown in the present study. It is observed from the spectra that both pure and CdS doped KDP crystals exhibit low cut off wave lengths and good transmittances towards the visible and infrared regions. The optical transmission percentages and cut off wavelengths observed are provided in Table 3. The transparent nature of these crystals observed is a desirable property for these crystals to have NLO applications.

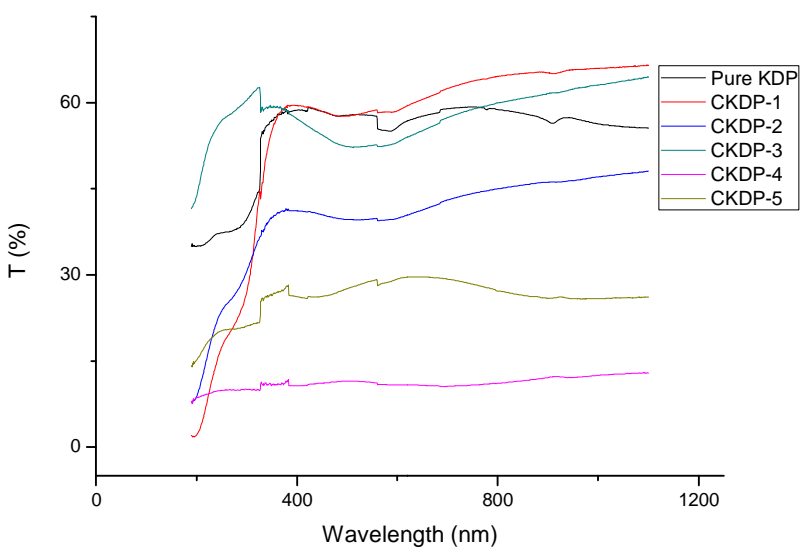

Fig-5: UV-Vis-NIR spectra observed for the pure and CdS doped KDP crystals 
Table-3: The cut off wavelengths, optical transmission percentages, SHG efficiencies and work hardening coefficients (n)

\begin{tabular}{|c|c|c|c|c|}
\hline Crystal & $\begin{array}{c}\text { Cut off } \\
\text { wavelength } \\
(\mathrm{nm})\end{array}$ & $\begin{array}{c}\text { Optical } \\
\text { transmission } \\
(\%)\end{array}$ & $\begin{array}{c}\text { SHG } \\
\text { efficiency }\end{array}$ & $\begin{array}{c}\text { Work } \\
\text { hardening } \\
\text { coefficient }\end{array}$ \\
\hline Pure KDP & 330 & 58 & 1.00 & 2.6 \\
\hline CKDP-1 & 260 & 67 & 2.00 & 2.7 \\
\hline CKDP-2 & 292 & 45 & 1.61 & 1.6 \\
\hline CKDP-3 & 300 & 65 & 0.94 & 3.3 \\
\hline CKDP-4 & 307 & 13 & 1.88 & 3.3 \\
\hline CKDP-5 & 340 & 30 & 2.38 & 2.9 \\
\hline
\end{tabular}

The SHG efficiencies observed are given in the Table 3. It can be seen that the SHG efficiency increases significantly due to CdS doping.

Figure 6(a) shows the variation of Vicker hardness number $\left(\mathrm{H}_{\mathrm{v}}\right)$ with applied load $(\mathrm{P})$ for the pure and CdS doped KDP crystals grown in the present study. The hardness of a material is a measure of its resistance it offers to local deformations [28]. The micro-indentation test is a useful method for studying the nature of plastic flow and its influence on the deformation of the materials. Higher hardness value of a crystal indicates that greater stress is required to create dislocation [51].
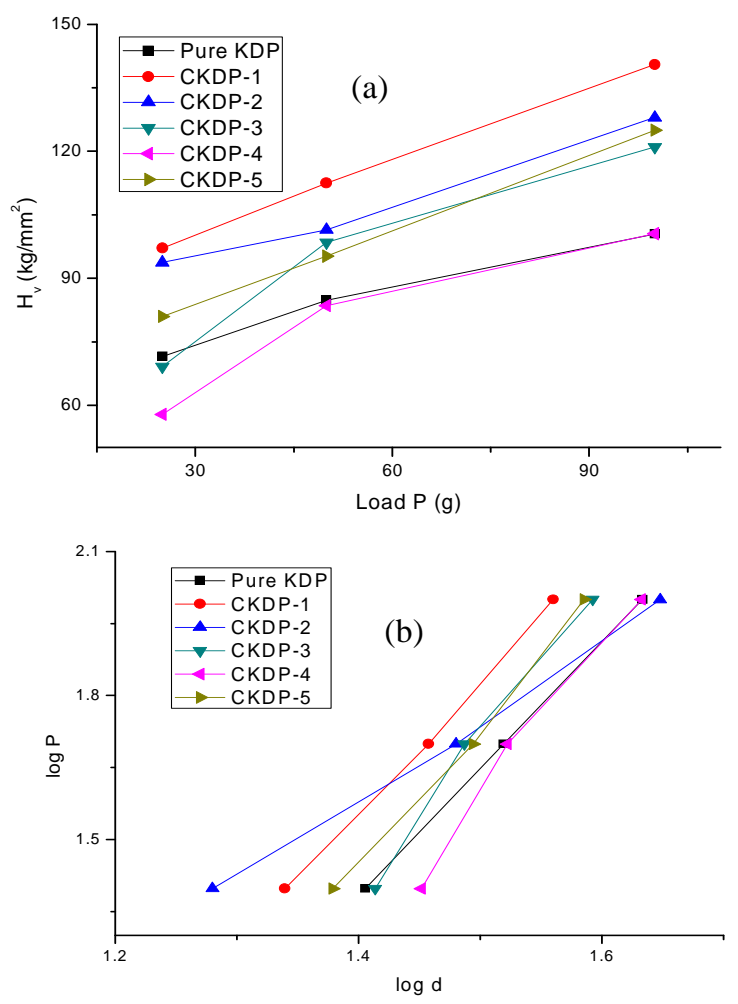

Fig-6: Results of microhardness measurements: (a) Hardness number $\left(\mathrm{H}_{\mathrm{v}}\right)$ verses load $(\mathrm{P})$ plots and $(\mathrm{b}) \log \mathrm{P}$ verses $\log \mathrm{d}$ plots
The $\log \mathrm{P}$ verses $\log \mathrm{d}$ plots ( $\mathrm{d}$ is the average diagonal length of the indentation made) were also made and are shown in Figure $6(\mathrm{~b})$. The plots are found to be nearly straight line. From the slope of the best fitted lines, the work hardening coefficients or Meyer indices (n) were obtained and are given in Table 3.

Results obtained in the present study indicate that the $\mathrm{H}_{\mathrm{v}}$ value increases with the increasing load for all the six crystals grown. The $\mathrm{H}_{\mathrm{v}}$ value increases upto a load of $100 \mathrm{~g}$, above which cracks start developing which may be due to the release of internal stress generation with indentation. The Vicker hardness number $\left(\mathrm{H}_{v}\right)$ is defined as

$$
\mathrm{H}_{\mathrm{v}}=1.8544 \mathrm{P} / \mathrm{d}^{2} \mathrm{~kg} / \mathrm{mm}^{2}
$$

and the Meyer's law [52] is expressed as

$$
\mathrm{P}=\mathrm{k}_{1} \mathrm{~d}^{\mathrm{n}}
$$

where $\mathrm{k}_{1}$ is the material constant.

According to Onitsch and Hanneman ' $\mathrm{n}$ ' should lie between 1.0 and 1.6 for hard material and above 1.6 for soft ones [52]. The ' $n$ ' values observed in the present study are more than 1.6. This indicates that all the six crystals grown belong to soft materials category.

\subsection{Electrical Properties}

The dielectric parameters, viz. DC electrical conductivity $\left(\sigma_{\mathrm{dc}}\right)$, dielectric constant $\left(\varepsilon_{\mathrm{r}}\right)$, dielectric loss factor $(\tan \delta)$ and AC conductivity $\left(\sigma_{\mathrm{ac}}\right)$ values obtained in the present study are shown in Figures 7-10. It can be seen that all the four parameters increase with the increase in temperature. However, no systematic variation is observed with the impurity concentration (volume of $\mathrm{CdS}$ solution added to the KDP solution used for the growth of single crystals) for all the above electrical parameters (except for $\sigma_{\mathrm{dc}}$ along a-direction) in the whole temperature range considered in the present study. This is illustrated in Figures 11-14. $\sigma_{\mathrm{dc}}$ along a-direction decreases with the increase in $\mathrm{CdS}$ concentration. Moreover, 
the $\varepsilon_{\mathrm{r}}$ values (along both a- and c- directions) observed for the $\mathrm{CdS}$ doped crystal are less than that observed for the pure KDP. The variation with CdS concentration is nonlinear. The decrease of $\varepsilon_{\mathrm{r}}$ value due to $\mathrm{CdS}$ addition indicates the improvement in NLO property. This is in agreement with the SHG efficiencies observed.

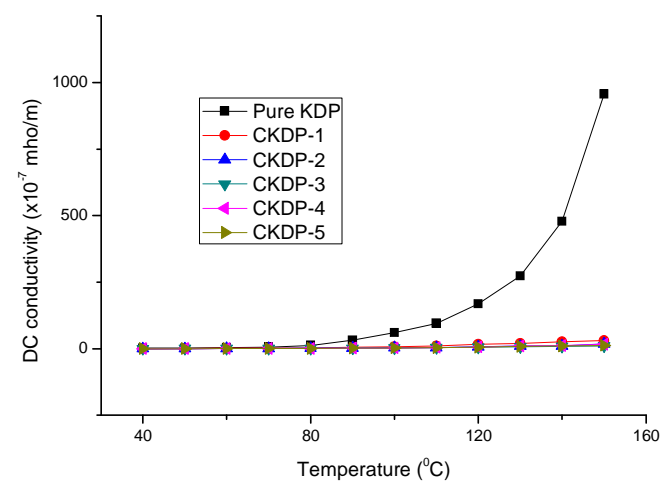

Along a- direction

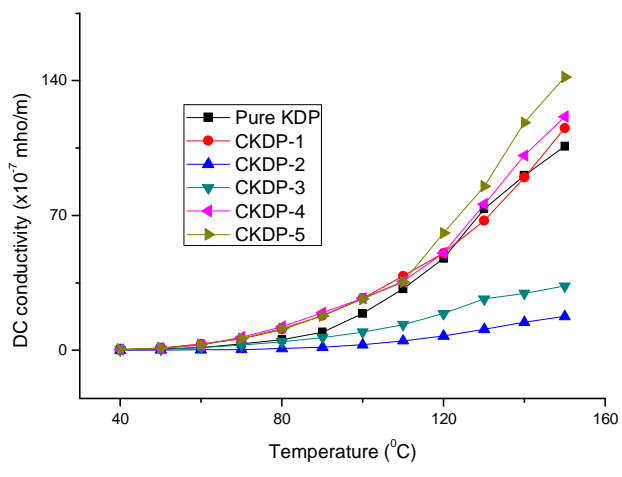

Along c- direction

Fig-7: DC electrical conductivities $\left(\sigma_{\mathrm{dc}}\right)$ observed for the pure and CdS doped KDP crystals

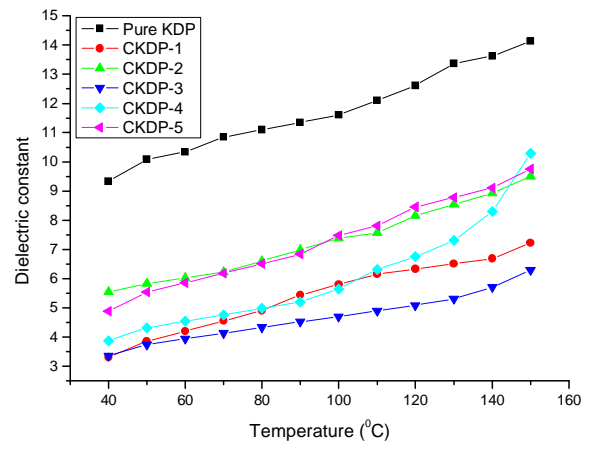

Along a- direction

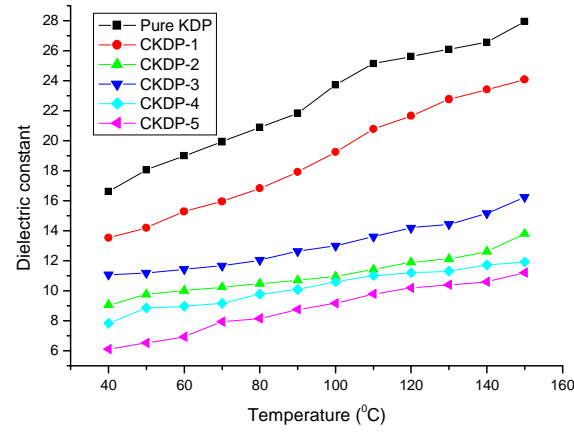

Along c- direction

Fig-8: Dielectric constants $\left(\varepsilon_{\mathrm{r}}\right)$ observed for the pure and CdS doped KDP crystals

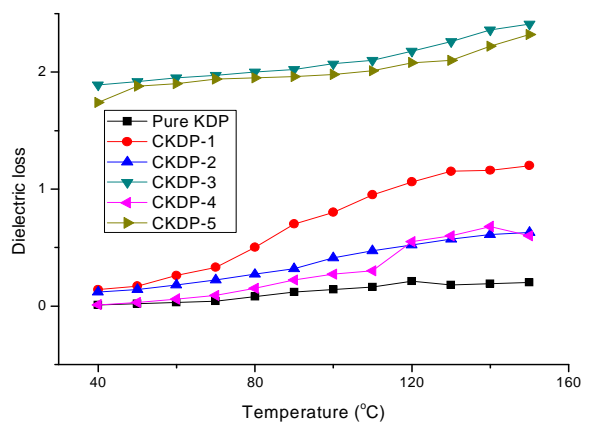

Along a- direction

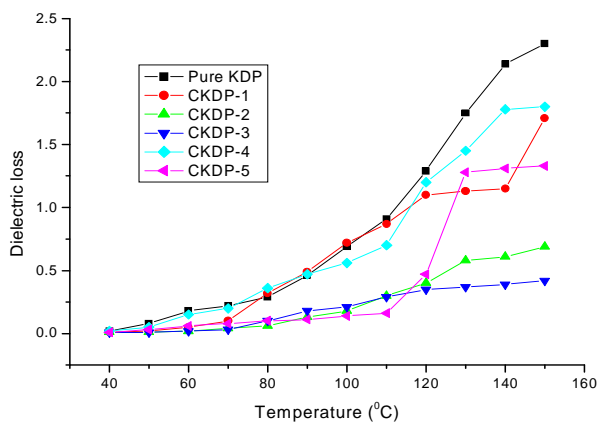

Along c- direction

Fig-9: Dielectric loss factors $(\tan \delta$ ) observed for the pure and CdS doped KDP crystals 


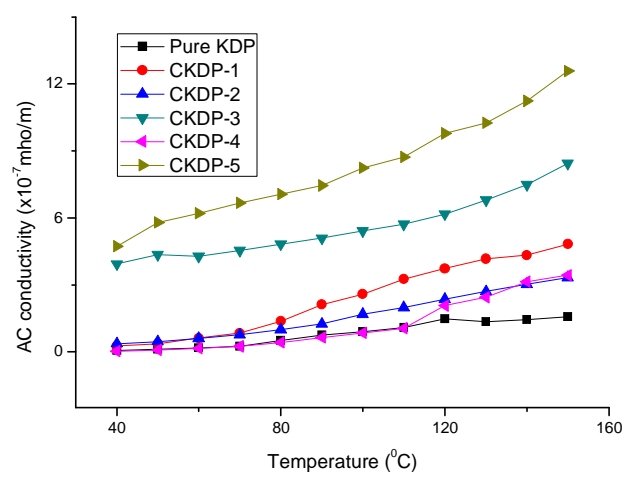

Along a- direction

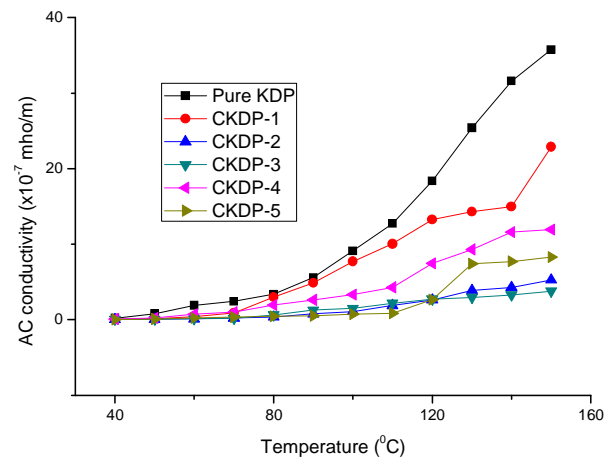

Along c- direction

Fig-10: AC electrical conductivities $\left(\sigma_{\mathrm{ac}}\right)$ observed for the pure and CdS doped KDP crystals

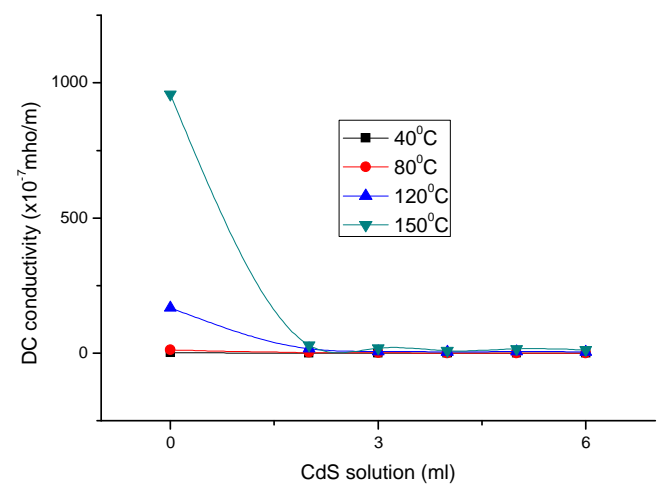

Along a- direction

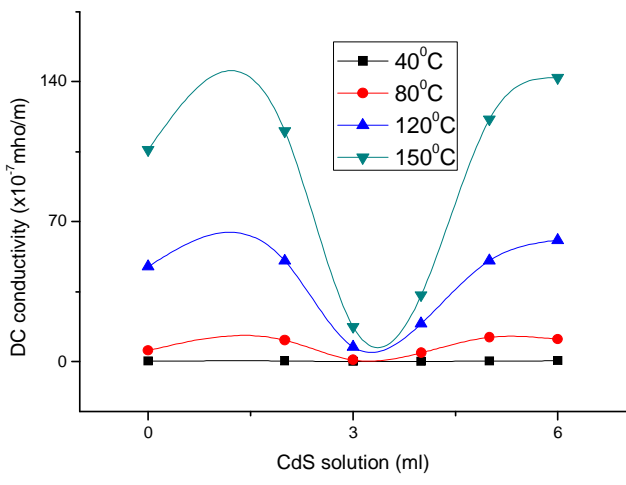

Along c- direction

Fig-11: Impurity concentration dependence of $\sigma_{\mathrm{dc}}$ observed for the pure and CdS doped KDP crystals

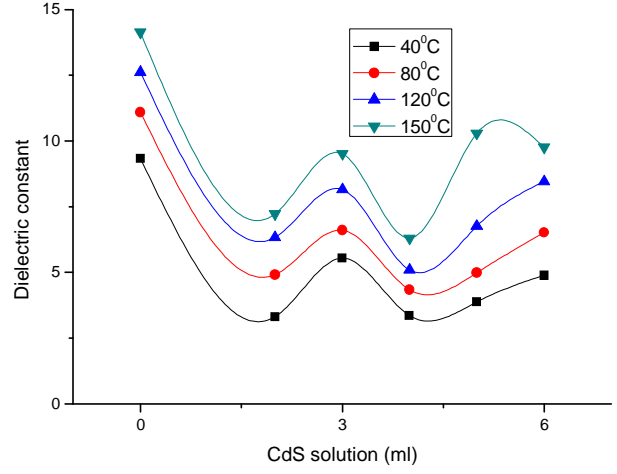

Along a- direction

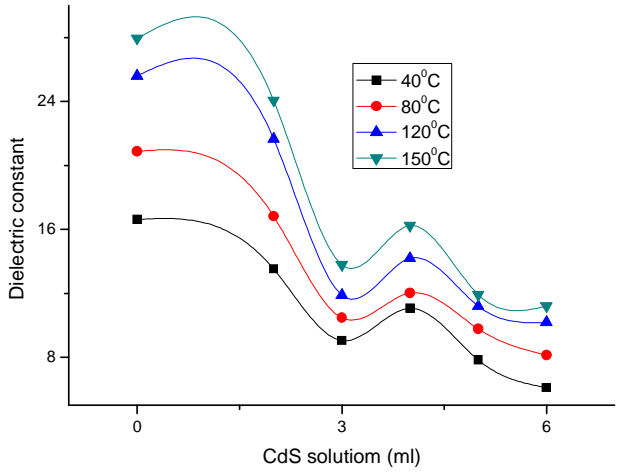

Along c- direction

Fig-12: Impurity concentration dependence of $\varepsilon_{\mathrm{r}}$ observed for the pure and CdS doped KDP crystals 


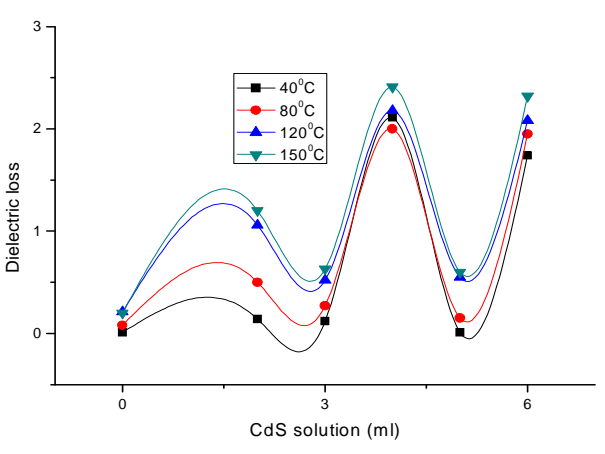

Along a- direction

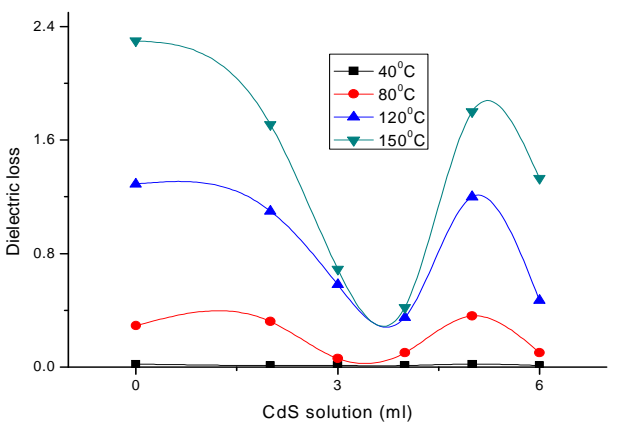

Along c- direction

Fig-13: Impurity concentration dependence of $\tan \delta$ observed for the pure and CdS doped KDP crystals

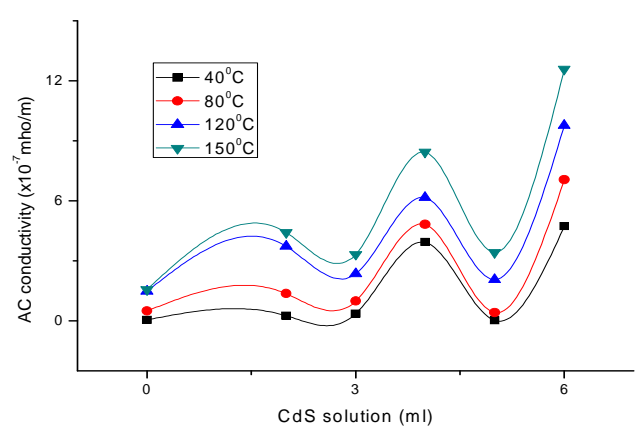

Along a- direction

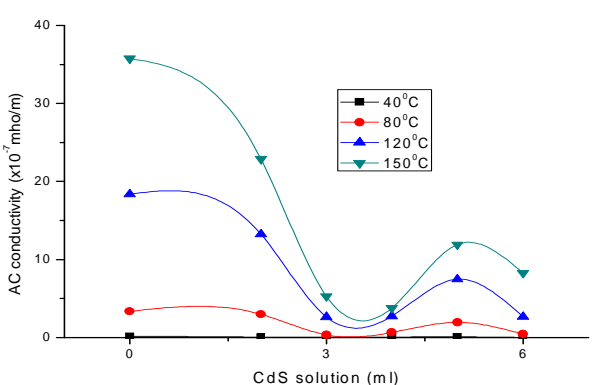

Along c- direction

Fig-14: Impurity concentration dependence of $\sigma_{\mathrm{ac}}$ observed for the pure and CdS doped KDP crystals

The experimental data and especially the character of the temperature dependence of electrical conductivity allowed the earlier workers to understand that the electrical conductivity of KDP crystals is determined by both the thermally generated L-defects (vacant hydrogen bonds) and the foreign impurities incorporated into the lattice and generating L-defects there [53]. When performing measurements, Lokshin [54] assumed that $\mathrm{HPO}_{4}{ }^{2-}$ ions are also responsible for the formation of vacant hydrogen bonds (L-defects). Therefore, the $\mathrm{pH}$ value of the initial solution, which determines its ionic composition, can be one of the most important factors that affect crystal conductivity, because of the $\mathrm{HPO}_{4}{ }^{2-}$ ion concentration in the solution at some $\mathrm{pH}$ is higher by several orders of maginitude than the concentration of any other impurity [55]. From the above, it can be understood that the proton transport depends on the generation of L-defects. Hence, the increase of conductivity with the increase in temperature observed for CdS doped KDP crystals in the present study can be understood as due to the temperature dependence of the proton transport. Also, the conductivity increases smoothly through the temperature range considered in the present study.
Plots between $\ln \sigma_{\mathrm{dc}}$ and $10^{3} / \mathrm{T}$ and between $\ln \sigma_{\mathrm{ac}}$ and $10^{3} / \mathrm{T}$ (not shown here) are found to be nearly linear. So, the conductivity (DC and AC) values were fitted correspondingly to the Arrhenius relation:

$$
\begin{gathered}
\sigma_{\mathrm{dc}}=\sigma_{0 \mathrm{dc}} \exp \left[-\mathrm{E}_{\mathrm{dc}} /(\mathrm{kT})\right] \\
\text { and } \sigma_{\mathrm{ac}}=\sigma_{0 \mathrm{ac}} \exp \left[-\mathrm{E}_{\mathrm{ac}} /(\mathrm{kT})\right],
\end{gathered}
$$

where $\sigma_{0 \mathrm{dc}}$ and $\sigma_{0 \mathrm{ac}}$ are the proportionality constant (considered to be the characteristic constant of the material), $\mathrm{k}$ is the Boltzman constant and $\mathrm{T}$ is the absolute temperature. The DC and AC activation energies $\left(E_{d c}\right.$ and $\left.E_{a c}\right)$ were estimated using the slope of the corresponding line plots. The estimated DC and AC activation energies for the pure and CdS doped KDP crystals grown in the present study are given in Table 4. The $E_{\mathrm{dc}}$ values are observed to be more than the $\mathrm{E}_{\mathrm{ac}}$ values as expected. The low values of $E_{d c}$ and $E_{a c}$ observed suggests that oxygen vacancies may be responsible for 
conduction in the temperature region considered in the present study.

Table-4: The activation energies $\left(\mathrm{E}_{\mathrm{ac}}\right.$ and $\left.\mathrm{E}_{\mathrm{dc}}\right)$ estimated for pure and CdS doped KDP crystals

\begin{tabular}{|c|c|c|c|c|}
\hline \multirow{2}{*}{ Crystal } & \multicolumn{4}{|c|}{ Activation energies (eV) } \\
\cline { 2 - 5 } & Along a-direction & \multicolumn{2}{c|}{ Along c-direction } \\
\cline { 2 - 5 } & $\mathrm{E}_{\mathrm{ac}}$ & $\mathrm{E}_{\mathrm{dc}}$ & $\mathrm{E}_{\mathrm{ac}}$ & $\mathrm{E}_{\mathrm{dc}}$ \\
\hline Pure KDP & 0.148 & 0.275 & 0.209 & 0.260 \\
\hline CKDP-1 & 0.133 & 0.225 & 0.232 & 0.249 \\
\hline CKDP-2 & 0.101 & 0.240 & 0.223 & 0.262 \\
\hline CKDP-3 & 0.031 & 0.223 & 0.204 & 0.217 \\
\hline CKDP-4 & 0.208 & 0.235 & 0.202 & 0.248 \\
\hline CKDP-5 & 0.038 & 0.281 & 0.226 & 0.238 \\
\hline
\end{tabular}

Variation of dielectric constant with temperature is generally attributed to the crystal expansion, the electronic and ionic polarizations and the presence of impurities and crystal defects. The variation of $\varepsilon_{\mathrm{r}}$ at lower temperatures is mainly due to the crystal expansion and electronic and ionic polarizations. The increase of $\varepsilon_{\mathrm{r}}$ at higher temperatures is mainly attributed to the thermally generated charge carriers and impurity dipoles. It has been shown by Varotsos [56] that the electronic polarizability practically remains constant in the case of ionic crystals. So, the increase in dielectric constant with temperature is essentially due to the temperature variation of ionic polarizability.

The CdS is an ionic substance and is expected to become $\mathrm{Cd}^{2+}$ and $\mathrm{S}^{2-}$ ions in the solution. In the KDP crystal matrix, some of these ions are expected to occupy interstitial positions. This induces bulk defect states due to competition in getting the sites for the impurity ions to occupy. To some extent, the impurity ions are expected to replace the ions in KDP. So, it is expected to create a random disturbance in the hydrogen bonding system in the KDP crystal matrix. As the conduction in KDP crystal is protonic, the random disturbance in the hydrogen bonding system may cause the electrical parameters to vary nonlinealy with the impurity concentration.

\section{CONCLUSIONS}

Ethylene diamine capped CdS nanoparticles were prepared by a simple solvothermal method using a domestic microwave oven. As CdS nanoparticles prepared were found to be slightly soluble in water $(0.33 \mathrm{~g} / 100 \mathrm{ml}$ of water $), \mathrm{CdS}$ doped KDP single crystals could be successfully grown by the free evaporation method from aqueous solutions at room temperature. The six grown crystals were characterized structurally, chemically, thermally, optically, mechanically and electrically. Results obtained indicate that the impurity molecules have entered into the KDP crystal matrix. CdS doping have been found to enhance the SHG efficiency and tune the optical and electrical properties significantly.

\section{REFERENCES}

[1] S.S.Hussaini, N.R.Dhumane, V.G.Dongre, P.Ghughare and M.D. Shirsat, Optoelectronics and Advanced Materials, 112, 707, (2007)

[2] B.Suresh Kumar and Rajendra Badu, Indian Journal of Pure and Applied Physics, 46, 123, (2008)

[3] K.D.Parikh, D.J.Dava, B.B.Parekh and M.J.Joshi, Cryst.Res.Technol., 45(6), 603, (2010)

[4] Ferdousi Akhtar and Jiban Podder, Journal of Crystallization Process and Technology, 3, 55, (2011)

[5] P.Jagadish and N.P.Rajesh, J. Optoele. and Adv. Mat., 13, 962, (2011)

[6] G.G.Muley, Journal of Science and Technology, 2(5), 109, (2012)

[7] N.Kanagathara and G.Anbalagan, International Journal of Optics, 2012, (2012)

[8] P.Kumarasen, S.Moorthy Babu and P.M.Anbarasan, Journal of Optical Materials, 30(9), 1368, (2001)

[9] L.M.Perez, M.E.Fernandiz, J.E.Diosa and R.A.Vargas, Revista colomb. De Fisica, 37, 86, (2005)

[10] P.Kumaresan, S.Moorthy Babu and P.M.Anbarasan, $4^{\text {th }}$ DAE-BRNS Laser Symposium, 4, 521, (2005)

[11] G.Bhagavannarayanna, S.Parthiban and S.Meenakshi Sundaran, Cryst. Growth. Des., 8, 446, (2008)

[12] I.Pritula, V.Gayvoronsky, M.Kopylovsky, M.Kolybaeva, V.Puzikov, A.Kosinova, T.Tkachenko, V.Tsurikov, T.Konstantiniva and V.Pugibko, J. Funct. Mater., 15, 420, (2008)

[13] Igor Pritula, Vladimir Gayvoronsky, Maria Kolybaeva, Viacheslav Puzikov, Mykhayl Brodyn, Valentin Tkachenko, Anna Kosinova, Maksim Kopylovsky, Vitaliy Tsurikov and Olga Bezkrovnaya, Journal of Optical Materials, 33, 623, (2011)

[14] I.Pritula, O.Bezkrovnaya, M.Kolybaeva, A.Kosinova, D.Sofrononov, V.Tkachenko and V.Tsurikov, Material Chemistry and Physics, 129, 777, (2011)

[15] Valentin G.Grachev, Lan.A.Vrable, Galina, I.Malovichko, Igor M.Pritula, Olga N.Bezkrovnaya, Anna V. Kosinova, Vasyl O.Yatsyna and Vladimir Ya. Gayvoronsky, J.Appl.Phys., 112, 014107, (2012) V.Ya Gayvoronsky, M.A. Kopylovsky, M.S.Brodyn, I.M.Pritula, M.I.Kolybaeva and V.M.Puzikov, Laser Phys.Lett., 10, 035401, (2013)

[17] I.Pritula, A.Kosinova, D.A.Vorontsov, M.I. Kolybaeva, O.N.Bezkrovnaya, V.F.Tkachenko, O.M.Vovk and E.V.Grishina, Journal of Crystal Growth, 355, 26, (2012)

[18] O.Conde, A.G.Rolo, M.J.M.Gomes, Ricolleau and D.J.Barber, Journal of Crystal Growth, 247, 371, (2003)

[19] A.Meldrum, C.V.White, L.A.Boatner, I.M.Anderson, R.A.Zuhr, E.Sonder, J.D.Budai and D.O.Anderson, Nucl. Ins.Meth.Phys.Res., B148, 957, (1999) 
[20] P.Maly and T.Miyoshi, J.Lumin., 90, 129, (2000)

[21] T.M.Hayes, L.B.Lurio, J.Pant and P.D.Persans, Solid State Comm., 117, 627, (2001)

[22] O.Halimi, B.Boudine, M.Sebais, A.Chellouche, R.Mouras and A.Boudrioua, Material Science and Engineering, C23, 1111, (2003)

[23] B.Boudine, M.Sebais, O.Halimi, H.Alliouche, A.Boudrioua and R.Mouras, Catalysis Today, 89, 293, (2004)

[24] B.Boudine, M.Sebais, O.Halimi, R.Mouras, A.Boudrioua and P.Bourson, Optical Materials, 25, 373, (2004)

[25] A.Bensouici, J.L.Plaza, E.Dieguez, O.Halimi, B. Boudine, S.Addala, L.Guerbous and M.Sebais, J. Lumin., 129, 948, (2009)

[26] A.Bensouici, J.L.Plaza, O.Halimi, B.Boudine, M.Sebais and E.Dieguez, Journal of Optoelectronics and Advanced Materials, 10(11), 3051, (2008)

[27] K.Balasubramanian, P.Selvarajan and E.Kumar, Indian Journal of Science and Technology, 3(1), 41, (2010)

[28] M.V.Artemyev, V.Sperling and U.Woggon, Journal of Crystal Growth, 19, 184, (1998)

[29] B.Ullrich, D.M.Bagnall and H.Segawa, J.Lumin., 1162, 87, (2000)

[30] K.S.Ramaiah, R.D.Pilkington, A.E.Hill, R.D.Tomlinson and A.K.Bhatnagar, Mater.Chem.Phys., 68, 22, (2001)

[31] M.V.Artemyev, V.Sperling and U.Woggon, J.Appl.Phys., 81(10), 6975, (1997)

[32] V.Nair Selvakumar and T.Tagahara, Phys. Rev., 355 (8), 5156, (1997)

[33] Y.Andrew Wang, J.Jack Li, Haiyan Chen and Xiaogang Peng, J. Am.Chem.Soc.,124, 2293, (2002)

[34] Wenzhou Guo, J.Jack Li, Y.Andrew Wang and Xiaogang Peng, Chem. Mater.,15, 3125, (2003)

[35] Huixiang Tang, Mi Yan, Hui Zhang, Mingzhe Xia and Deren Yang, Mater. Lett., 59, 1024, (2005)

[36] R.S.S.Saravanan and C.K.Mahadevan, J.Alloys and Compounds, 541, 115, (2012)

[37] S.I.Srikrishna Ramya and C.K.Mahadevan, Mater.lett., 89, 111, (2012)

[38] S.Nagaveena and C.K.Mahadevan, J.Alloys and Compounds, 582, 447, (2013)

[39] H.Lipson and H.Steeple, Interpretation of X-ray powder diffraction patterns (Newyork, Mac Millan,1970)

[40] S.K.Kurtz and T.T.Perry, Appl. Phys., 39, 3798, (1968)

[41] T.H Freeda and C.K Mahadevan, Bull.Mater.Sci., 23, 335, (2000)

[42] S.Perumal and C.K Mahadevan, Physica B, 367, 172, (2005)

[43] G.Selvarajan and C.K Mahadevan, J.Mater.Sci., 41, 8218, (2006)
[44] S.Goma, C.M.Padma and C.K.Mahadevan, Mater.Lett., 60, 3701, (2006)

[45] N.Manonmani, C.K.Mahadevan, and V.Umayourbhagan, Mater. Manuf. Process, 22, 388, (2007)

[46] M.Meena and C.K.Mahadevan, Cryst.Res.Technol., 43, 116, (2008)

[47] M. Priya and C.K.Mahadevan, Physica B, 403, 67, (2008)

[48] M.Meena and C.K.Mahadevan, Mater.Lett., 62, 3742, (2008)

[49] T.H Freeda and C.K.Mahadevan, Pramana-J. Phys., 57, 829, (2001)

[50] F.Loretta, T.Josephine Rani, P.Selvarajan, S.Perumal and S.Ramalingom, World J. Sci.Technol., 1(3), 1, (2011)

[51] P.Rajesh and P.Ramasamy, Physica B, 404, 1611, (2009)

[52] S.Karan and S.P.Sen Gupta , Mater.Sci.Eng., A398, 198, (2005)

[53] L.B.Haris and G.J.Vella, Journal of Applied Physics, 37 (11), 4294, (1967)

[54] E.P.Lokshin, Crystallogr.Rep., 41, 1070, (1996)

[55] E.P.Lokshin, Crystallogr.Rep., 41, 1061, (1996)

[56] P.Varotsos, J.Phys.Lett., 39, L79, (1978)

\section{BIOGRAPHIES}

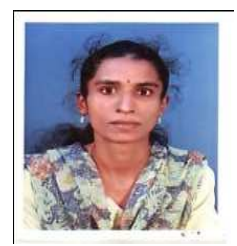

O.V.Mary Sheeja, born in Colachel, India in 1982 has acquired her academic degrees B.Sc. (Physics, 2002), M.Sc. (Physics, 2004), M.Phil. (Physics, 2006) from Manonmanium Sundaranar University. Currently she is a Ph.D research Scholar of Manonmanium Sundaranar University. She has about 3 years research experience and her research area is crystal growth and characterization.

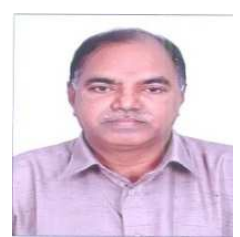

C.K.Mahadevan, born in Nagercoil, India in 1958 has acquired B.Sc. (1978), M.Sc.(1980), Ph.D.(1984) and D.Sc. (2002) degrees in Physics from reputed institutions in India. After serving for some time in different places in India and USA, he started his long service in S.T.Hindu College, Nagercoil in 1987 and has been there till Date. He has more than 27 years teaching experience (taught B.Sc., M.Sc., M.Phil and Ph.D. students) and 32 years research experience (guided $30 \mathrm{Ph} . \mathrm{D}$. projects, published 1 review article and 180 research papers in International journals and delivered 57 invited talks in national/international conferences). His major research area is Crystalline and Nanostructured Materials Science (Materials Synthesis and Characterization). He is a winner of several coveted awards and honours for his teaching, research and related activities. 